\title{
A study of thyroid profile in cases of primary infertility attending a tertiary care hospital of south India
}

\author{
Anitha Nirakari B.* \\ Department of Obstetrics and Gynecology, Nijalingappa Medical College, HSK Hospital and Research Centre, \\ Bagalkot, Karnataka, India
}

Received: 01 May 2018

Accepted: 05 May 2018

*Correspondence:

Dr. Anitha Nikari,

E-mail: sujatha2481@gmail.com

Copyright: $\odot$ the author(s), publisher and licensee Medip Academy. This is an open-access article distributed under the terms of the Creative Commons Attribution Non-Commercial License, which permits unrestricted non-commercial use, distribution, and reproduction in any medium, provided the original work is properly cited.

\begin{abstract}
Background: Infertility is a rising major problem affecting more than 50 million couples globally every year. Endocrine as well as immune system abnormalities can impair the fertility. Most of the studies globally indicated association of infertility with multiple factors like stress, luteal phase defects, structural and functional reproductive disturbances. Many infertile women with thyroid dysfunction had associated hyperprolactinemia with increases TSH in ovulatory dysfunction. The aim of the present study was to determine the association of hypo and hyperthyroidism with infertility among cases of primary infertility in women.

Methods: A cross sectional study was conducted among the patients attending the infertility clinic for the first time. The study was approved by the institutional ethical committee and the study was carried as per the guidelines of the ethical committee. The serum levels of T3, T4 and TSH were estimated and Prolactin in cases where necessary by Chemiluminiscence immunoassay. The data was analyzed by using the unpaired " $\mathrm{t}$ " test. A 'p' value $<0.05$ was considered significant.

Results: 285 cases were enrolled and majority (38.6\%) was in 31-34 age groups with mean age of $24.2 \pm 1.6$ years. $30.53 \%$ were found with thyroid dysfunction. Majority $(16.49 \%)$ were found with subclinical hypothyroid, followed in order by primary hypothyroid $(9.82 \%)$, subclinical hyperthyroid $(2.11 \%)$, primary hyperthyroid $(1.05 \%)$, secondary hypothyroid $(0.70 \%)$ and secondary hyperthyroid $(0.35 \%)$.

Conclusions: To conclude, thyroid dysfunction is a common cause of infertility and can be easily managed by correcting the levels of thyroid hormones. Present study suggests that thyroid replacement therapy in subclinical hypothyroidism at an early stage is justified in infertile women. Borderline variations in TSH levels should not be ignored in infertile women who are otherwise asymptomatic for subclinical hypothyroidism. Hence for better management of cases of primary infertility studies with large sample size and long term follow up are required to validate and justify the variation in TSH and prolactin levels.
\end{abstract}

Keywords: Hyperprolactinemia, Infertility, Subclinical hypothyroidism, Thyroid dysfunction

\section{INTRODUCTION}

Infertility is a rising major problem affecting more than 50 million couples globally every year. The major causes listed are variable from region to region and place to place. India is one of the countries facing a serious rise in the cases of infertility every year. According to WHO estimates the overall prevalence of infertility in India ranges to $3.5 \%-16.8 \% .^{1}$ The types of infertility are primary who are unable to conceive after one year of marriage whereas secondary refers to the cases who had earlier had a child but unable to conceive thereafter. Multiple causes affect the fertility of the female. Endocrine as well as immune system abnormalities can 
impair the fertility. Among the endocrine glands, thyroid gland dysfunctions can affect the numerous aspects of pregnancy and reproduction. ${ }^{2}$

Thyroid dysfunction can affect the fertility in various ways which include anovulatory cycles, luteal phase defects, high prolactin levels and sex hormone imbalances. Thyroid evaluation can be done in any woman who wants to conceive with a family history of thyroid disorder, had miscarriages regularly, or unable to conceive after one year of unprotected sexual intercourse. In hypothyroidism there is deficiency of factors VII, VIII, IX and XI and estrogen break through bleeding secondary to anovulation which will explain the cause of frequent, prolonged and heavy menstruation. ${ }^{3}$

Hyperthyroidism is characterized by frequent scanty menstruation or amenorrhea. Thyrotoxicosis increases the risk of spontaneous abortions and increases the risk of congenital anomalies and aplasia cutis. Most of the studies globally indicated association of infertility with multiple factors like stress, luteal phase defects, structional and functional reproductive disturbances. Many infertile women with thyroid dysfunction had associated hyperprolactinemia with increases TSH in ovulatory dysfunction. ${ }^{4}$ Most of the studies conducted earlier had studied association of thyroid function with prolactin dysfunction. The aim of the present study was to determine the association of hypo and hyperthyroidism with infertility among cases of primary infertility in women.

\section{METHODS}

A cross sectional study was conducted at a tertiary care hospital for a period of one year from January 2015 to December 2016 in Department of Gynecology and Obstetrics. All the patients attending the infertility clinic for the first time during the study period were enrolled and cases fulfilling the inclusion criteria were included in the study. The socio demographic data, family history, age, duration of marriage and all possible risk factors were enquired and noted in a separate questionnaire sheet prepared for the study.

The study was approved by the institutional ethical committee and the study was carried as per the guidelines of the ethical committee. The details of the study were clearly explained to the participants and informed consent was taken from all the study cases, and those who were not willing for consent were excluded from the study.

The inclusion criteria were cases of primary infertility, age between 20-40 years with duration of marriage more than one year. Cases with an old history of thyroid surgery, on thyroid medications or benign thyroid disease were excluded and also cases with confirmed male cases of infertility. Females with secondary causes of infertility like tubular blockage, pelvic inflammatory disease, endometriosis, with associated liver or renal diseases were excluded from the study. The protocol workup for cases of primary infertility was a detailed medical and marital history, a thorough gynecological examination, an Ultrasonography abdomen, premenstrual endometrial biopsy and a hormonal profile. (TSH, FT3 and FT4) Hysterosalpingography whenever indicated was performed.

All the cases were thoroughly examined by a gynecologist and findings were noted in the predesigned questionnaire and report sheet.

$5 \mathrm{ml}$ of venous blood sample was collected from all the included cases and dispensed into sterile plain vacutainers. Allowed to clot and serum was collected by centrifuging at 5000rpm. The sera were stored at $-200 \mathrm{c}$ till used for thyroid assay. (TSH, FT3 and FT4) The Thyroid assay was performed by Chemiluminiscence assay using Acculite CLIA micro wells. The assay reliability was determined using commercially derived control sera of low and high concentrations. Hyperthyroidism was diagnosed if serum TSH was $<0.3$ $\mathrm{mIU} / \mathrm{L}$ and hypothyroidism was diagnosed if serum TSH was $>4.0 \mathrm{mIU} / \mathrm{L}$. The total cases in the study were categorized into 7 types, based on the thyroid profile.

\section{Statistical analysis}

All the data was entered in Microsoft excel sheet and corrections were done. The analysis was done by using Graph pad prism version 4. The data was analyzed by using the unpaired " $t$ " test. A ' $p$ ' value $<0.05$ was considered significant.

\section{RESULTS}

A total of 780 cases during the study period of one year attended the infertility clinic of the hospital. All the cases were interviewed, and a detailed history and demographic data was collected and noted in the separate protocol sheet approved by institutional ethical committee. The cases were examined by gynecologist and clinical findings were noted. All the cases of primary infertility were included and other cases not fulfilling the inclusion criteria and cases of primary infertility who were not willing to participate in the study were also excluded.285 cases out of 780 cases were included in the study group. Table-1 explains the distribution of age pattern of the included cases. $38.6 \%$ of cases $(110 / 285)$ were in range of 31-34 followed in order by $25-30$ (26.67\%), 35-40 $(19.65 \%)$ and last in group of 20-24 (15.09\%) (Table-1).

Table 1: Age group of patients included in the study.

\begin{tabular}{|lll|}
\hline Age group & No & $\%$ \\
\hline $20-24$ & 43 & 15.09 \\
\hline $25-30$ & 76 & 26.67 \\
\hline $31-34$ & 110 & 38.60 \\
\hline $35-40$ & 56 & 19.65 \\
\hline Total & 285 & 100 \\
\hline
\end{tabular}


Mean age of the study subjects in our study was $24.2 \pm 1.6$ years. In our study, significance was not observed with relation to age and thyroid status in different groups. ( $p$ value > 0.05) $69.47 \%(198 / 285)$ cases in our study were euthyroid and $30.53 \%$ were found with Thyroid dysfunction. Among the cases with thyroid dysfunction, majority (16.49\%) were found with subclinical hypothyroid, followed in order by primary hypothyroid $(9.82 \%)$, subclinical hyperthyroid $(2.11 \%)$, primary hyperthyroid $(1.05 \%)$, secondary hypothyroid $(0.70 \%)$ and secondary hyperthyroid $(0.35 \%)$. The reference range for the cases is summarized in Table 2 .

Table 2: Categorization of cases based on thyroid profile.

\begin{tabular}{|c|c|c|c|}
\hline & FT3 (pmol/L) & FT4(pmol/L) & TSH (IU/ml) \\
\hline Euthyroid & $4.12-8.10$ & $10.10-28.14$ & $0.50-4.85$ \\
\hline Primary hypothyroid & $<4.12$ & $<10.10$ & $>4.85$ \\
\hline Primary hyperthyroid & $>8.1$ & $>28.14$ & $<0.5$ \\
\hline Secondary hypothyroid & $<4.12$ & $<10.10$ & $<0.5$ \\
\hline Secondary hyperthyroid & $>8.1$ & $>28.14$ & $>4.85$ \\
\hline Subclinical hypothyroid & $4.12-8.10$ & $10.10-28.14$ & $>4.85$ \\
\hline Subclinical hyperthyroid & $4.12-8.10$ & $10.10-28.14$ & $<0.5$ \\
\hline
\end{tabular}

Table 3: Distribution of cases according to thyroid status and mean of thyroid hormone.

\begin{tabular}{|llllll|}
\hline & No $(285)$ & $\%$ & FT3 $(\mathrm{pmol} / \mathrm{L})$ & FT4(pmol/L) & TSH $(\mathrm{IU} / \mathrm{ml})$ \\
& & & Mean \pm SD & Mean \pm SD & Mean \pm SD \\
\hline Euthyroid & 198 & 69.47 & $5.2 \pm 1.2$ & $15.2 \pm 3.1$ & $2.1 \pm 1.5$ \\
\hline Primary Hypothyroid & 28 & 9.82 & $2.1 \pm 1.0$ & $4.2 \pm 2.5$ & $11.0 \pm 2.1$ \\
\hline Primary Hyperthyroid & 3 & 1.05 & $14.2 \pm 1.5$ & $36.0 \pm 3.3$ & $0.4 \pm 0.1$ \\
\hline Secondary hypothyroid & 2 & 0.70 & $2.4 \pm 1.2$ & $5.1 \pm 0.2$ & $0.3 \pm 0.1$ \\
\hline Secondary Hyperthyroid & 1 & 0.35 & $15 \pm 1.4$ & $34 \pm 1.5$ & $9.2 \pm 1.1$ \\
\hline Subclinical hypothyroid & 47 & 16.49 & $5.5 \pm 1.2$ & $15.6 \pm 2.8$ & $9.4 \pm 1.0$ \\
\hline Subclinical hyperthyroid & 6 & 2.11 & $5.3 \pm 1.1$ & $16.0 \pm 1.5$ & $0.4 \pm 0.1$ \\
\hline
\end{tabular}

Most of the cases with thyroid dysfunction were found with menstrual disturbances. 87 cases of euthyroid patients, reported abnormal menstrual cycles in the history. Majority of the menstrual disturbance was amenorrhea. Prolactin levels were estimated in cases of thyroid dysfunction and found that 23 cases of 87 demonstrated hyperprolactinemia as an associated condition [Prolactin $>25 \mathrm{ng} / \mathrm{ml}$ ]. However infertile women with hypothyroidism had significantly higher levels of prolactin than other cases of thyroid dysfunction.

\section{DISCUSSION}

In the present study, $30.53 \%$ of cases were associated with Thyroid dysfunction with majority of the cases $(27.02 \%)$ with hypothyroidism. Hypothyroidism appears to be the common cause of infertility among the cases in the study with subclinical hypothyroidism being the most common among hypothyroid cases. Similar findings were also reported from many studies throughout the globe. This association of hypothyroidism for infertility was due to deficiency of iodine associated with low intake in developing countries. ${ }^{5}$ Most of the studies reported that mild iodine deficiency is associated with more hyperthyroidism and less hypothyroidism in the population. ${ }^{6}$ Few of the studies reported the prevalence of hypothyroidism is higher in pregnant woman than nonpregnant woman. Majority of the cases of euthyroid were observed with a shift towards the development of hypothyroidism in our study.

In our study majority of the cases of primary infertility were euthyroid, where the cause of infertility needs to be further investigated and prolactin assay was done in all the cases not associated with thyroid dysfunction. In our present study the prevalence of hypothyroidism is higher than the other studies of Arojoki M et al. ${ }^{7}$ But the results of our study with relation to high prevalence of hypothyroidism was compatible with the studies of Goswami B et al and Elahi S who also reported higher prevalence of subclinical hypothyroidism among primary infertility. ${ }^{8,9}$ Higher prevalence of infertility in hypothyroidism is due to disturbances in gonadotropin releasing hormone, and abnormal pulsatile release of LH. Some of the studies report that serum TSH levels can be a significant predictor of fertilization failure among women receiving IVF. ${ }^{10}$

Few studies reported that hyperprolactinemia was associated with thyroid disorders among infertile subjects 
as compared to females with normal fertility. In most of the cases subclinical hypothyroidism was associated with hyperprolactinemia. ${ }^{11}$ Hyperprolactinemia resulting from long standing primary hypothyroidism has been implicated in ovulatory dysfunctions ranging from inadequate corpus luteal progesterone secretion when mildly elevated to oligomenorrhoea when circulating progesterone levels are high. Likewise, our study revealed that majority had menstrual disturbances. ${ }^{12}$

\section{CONCLUSION}

Thyroid dysfunction is a common cause of infertility and can be easily managed by correcting the levels of thyroid hormones. Our study suggests that thyroid replacement therapy in subclinical hypothyroidism at an early stage is justified in infertile women. Borderline variations in TSH levels should not be ignored in infertile women who are otherwise asymptomatic for subclinical hypothyroidism. Hence for better management of cases of primary infertility studies with large sample size and long term follow up are required to validate and justify the variation in TSH and prolactin levels.

Funding: No funding sources Conflict of interest: None declared

Ethical approval: The study was approved by the Institutional Ethics Committee

\section{REFERENCES}

1. World Health Organization. Infecundity, Infertility and Childlessness in Developing Countries. DHS Comparative Reports No. 9. Calverton, Maryland, USA: ORC Marco and World Health Organization; 2004.

2. Poppe K, Velkeniers B, Glinoer D. The role of thyroid autoimmunity in fertility and pregnancy. Nat Clin Pract Endocrinol Metab. 2008;4:394-405.

3. Putowski L, Darmochwal-Kolarz D, Rolinski J, Oleszczuk J, Jakowicki J. The immunological profile of infertile women after repeated IVF failure (Preliminary study). Eur J Obstet Gynecol Reprod Biol. 2004;112:192-6.

4. Poppe K, Velkeniers B. Thyroid and Infertility. Verh K Acad Geneeskd Belg. 2002;64:389-99.

5. Bohnet HG, Fiedler K, Leidenberger FA. Subclinical hypothyroidism and infertility. Lancet. 1981;2:1278

6. Aghini LF, Antonangeli L, Martino E, Vitti P, MacCherini D, Leoli F, et al. The spectrum of thyroid disorders in an iodine-deficient community: the Pescopagano survey. J Clin Endocrinol Metabol. 1999;84:561-6.

7. Arojoki M, Jokimaa V, Juuti A, Koskinen P, Irjala $\mathrm{K}$, Anttila L. Hypothyroidism among infertile women in Finland. Gynecol Endocrinol 2000;14: 127-31.

8. Goswami B, Patel S, Chatterjee M, Koner BC, Saxena A. Correlation of Prolactin and Thyroid Hormone Concentration with Menstrual Patterns in Infertile Women. J Reprod Infertile. 2009;10:207-12.

9. Elahi S, Tasneem A, Nazir I, Nagra SA, Hyder SW. Thyroid dysfunction in infertile women. J Coll Physi Surg Pak. 2007; 17:191-4.

10. Cramer DW, Sluss PM, Powers RD, McShane P, Ginsburg ES, Hornstein MD, Vitonis AF, Barbieri RL. Serum prolactin and TSH in an in vitro fertilization population: is there a link between fertilization and thyroid function?. J Assist Reprod Genet. 2003;20:210-5.

11. Choudhary SD, Goswami A. Hyperprolactinemia and reproductive disorders- a profile from north east. J Assoc Physicians India. 1995;43:617-18.

12. Mishra R, Baveja R, Gupta V. Prolactin level in infertility with menstrual irregularities. J Obstet Gynecol India. 2002;52:40-3.

Cite this article as: Nirakari AB. A study of thyroid profile in cases of primary infertility attending a tertiary care hospital of south India. Int J Reprod Contracept Obstet Gynecol 2018;7:2180-3. 